\title{
Seismic Imaging by Impulse Response for Studying Crustal Structure of Central Tibet
}

\author{
Syed Mustafizur Rahman ${ }^{1}$, M. Rezaul Islam, and Mumnunul Keramat \\ Department of Applied Physics and Electronic Engineering, University of Rajshahi, Rajshai-6205, \\ Bangladesh
}

Received 3 September 2008, accepted in final revised form 16 December 2008

\begin{abstract}
Time-shifted source functions along with unwanted events produce the composite seismic trace. The time-shift varies according to the travel path of the source, which is reflected back from an interface. The arrival times of the reflected waves have been estimated as time-shifted sources in a technique with the application of Fourier transformation of composite seismic trace and source functions. Accurate time-shifts and amplitude coefficients are determined using the technique in the composite seismic traces. A very small time-shift has also been shown resolved. The technique is applied to INDEPTH seismic data and impulse responses are successfully obtained. Analyzed impulse response images have given the stratigraphic idea beneath the region of the central Tibet. High amplitude impressions in the implemented images have indicated the presence of a strong support that upholding the northern geology and high probability of further crustal change of the region. The technique impulse response is considered robust for the seismic reflection sequence analysis and can be used effectively for studying the subsurface geology.
\end{abstract}

Keywords: Seismic trace; Power spectrum; Impulse response; Reflection sequence; Subsurface geology.

(C) 2009 JSR Publications. ISSN: 2070-0237 (Print); 2070-0245 (Online). All rights reserved.

DOI: $10.3329 /$ jsr.vlil.1082

\section{Introduction}

The impulse response of a system is its output when presented with a very brief transient signal at its input. Seismic interpretation and data processing need to delineate accurate time position of the reflected sequences in the seismic traces. Impulse response can be effectively used in estimation of accurate time position of the time shifted sources in a seismic trace. Conventional seismic data processing is worked with amplitude. Seismic amplitude variation with offset (AVO) analysis had become common in petroleum exploration based on the fact that high intensity seismic reflections known as bright spots may be indicators of hydrocarbon accumulations, most typically the gas-bearing layer at

\footnotetext{
${ }^{1}$ Corresponding author: smrahman@eu.ac.bd
} 
top of a hydrocarbon trap [1, 2]. Many other interpretations can be suggested for the nature of different basement bright spots include melt bodies [3-5], aqueous fluid concentrations [6], solid mafic bodies [7], detachments at rheological boundaries [8, 9, 10], and imaging artifacts. Some of these interpretations are based on investigation of elastic properties [7], but usually the crucial arguments are based on the geological setting of the bright spots. The AVO analysis of reflection amplitude variation with offset has been the most important technique used to identify the fluids associated with these bright spots [11, 12]. However, conventional AVO modeling and analysis based on the Zoeppritz equations only work for a single interface, or for thick layers compared with dominant wavelength [13]. This paper attempts to study Tibetan bright spots using impulse response. A band of bright spot reflections has been imaged by the Project INDEPTH (International Deep Profiling of Tibet and the Himalayas) at about $15 \mathrm{~km}$ depth along $150 \mathrm{~km}$ of the northern Yadong-Gulu rift, southern Tibet [14-16].

The identification of seismic source in the seismic trace as impulses can be characterized with different stratigraphic layers. There are many filtering methodologies to differentiate unwanted signals in seismic data processing to identify the true reflection sequences. However, the work becomes complicated while very thin subsurface layers are present in the seismic section. Even two or more close reflections might be appeared as one reflection. Seismic wave propagating in an absorbing medium suffers from frequency dependant energy attenuation and phase distortion. Difference in layer thickness or a strong lateral change in interval velocity may produce a variation in seismic timing events [17]. This variation in spectral content of the seismic trace can be used to characterize the stochastic properties of the reflectivity. Time-frequency analyses of seismic data for the interpretation of subsurface geology [17-20] might be the examples of such characterization. Seismic trace is basically the function of various time shifted source functions. The present analysis is involved to identify the accurate time position of the seismic source in the traces as impulses. The impulse responses of synthetic seismic traces and real deep seismic profiles (Tib 6 and Tib 7) of INDEPTH II data (Fig. 1) are made in this work for better seismic images.

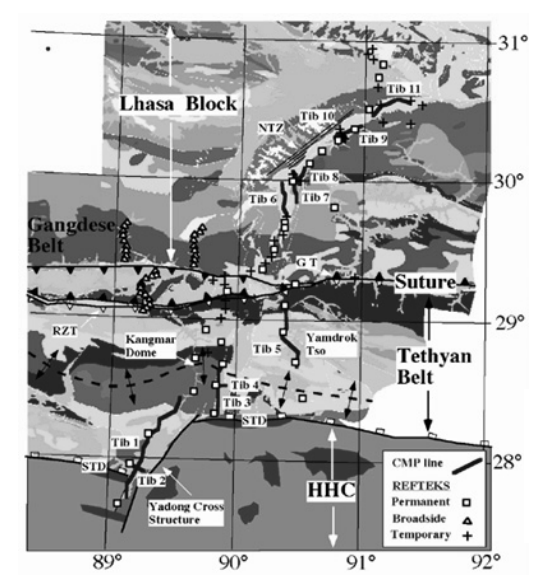

Fig. 1. Location map of the study area, blue dark lines indicate the project INDEPTH CMP profiles in the northern Yadong-Gulu rift (after Brown [21]). 


\section{FTTS Methodology}

Composite seismic traces are the record of amplitude with time. The variation of amplitude with time can be assumed to be related with subsurface properties. Geological interpretation can be obtained from the analysis of composite seismic traces according to reflections of source function present in the traces. As the contrast of the acoustic impedance and the thickness of the subsurface layers produce the reflections at different times in the traces, a technique is proposed here to explain the identification of appropriate time positions of reflections in the traces as impulses. A composite seismic trace, $y(t)$ can be written as [19]:

$$
y(t)=F\left[f(t)+a_{1} f\left(t-T_{1}\right)+a_{2} f\left(t-T_{2}\right)+\cdots \cdots+a_{n} f\left(t-T_{n}\right)\right]
$$

where, $f(t)$ is the source function and $f(t-T)$ is the reflected source functions. $T$ denotes the time shift that needs to travel the seismic wave from source to receiver and $a_{1}, a_{2}, a_{3} \ldots \ldots . . a_{n}$ are the amplitude coefficients varying with distance and absorbing media traveled by the wave.

Practical seismic source, $f(t)$ is an energy impulse or a vibrating source to generate waves with in the earth. The actual source used is dependent on the desired signal to noise ratio, the human environment, the target depth desired and the geological conditions. In the interpretation process of seismic sections, time-shift $T$ is determined the thickness and depth of different geologic strata using appropriate velocity analysis. The present technique is an approach to calculate the time-shift $T$ using the following analysis. Taking power spectrum using Fourier transformation of the seismic trace, Eq. (1), and after rearrangement it can be written as:

$$
\begin{aligned}
Y(\omega) & =F(\omega)+a_{1} e^{-j \omega T_{1}} F(\omega)+a_{2} e^{-j \omega T_{2}} F(\omega)+\cdots \cdots+a_{n} e^{-j \omega T_{n}} F(\omega) \\
& =\left[1+a_{1} e^{-j \omega T_{1}}+a_{2} e^{-j \omega T_{2}}+\cdots \cdots+a_{n} e^{-j \omega T_{n}}\right] F(\omega) \\
\text { or, } \quad Z(\omega) & =\frac{Y(\omega)}{F(\omega)}=1+a_{1} e^{-j \omega T_{1}}+a_{2} e^{-j \omega T_{2}}+\cdots \cdots+a_{n} e^{-j \omega T_{n}}
\end{aligned}
$$

which gives,

$$
z(t)=\delta(t)+a_{1} \delta\left(t-T_{1}\right)+a_{2} \delta\left(t-T_{2}\right)+\cdots \cdots+a_{n} \delta\left(t-T_{n}\right)
$$

where, $\delta(t-T)$ is the impulse responses. Therefore, the Eq. (3) is shown capable of calculating the time-shifts $T_{1}, T_{2}, \cdots T_{n}$ of respective impulses. The ratio of $Y(\omega)$ and $F(\omega)$, the Fourier transformations of trace and source (FTTS) are giving the time-shift $T$. That is why the analysis is termed in this paper as the FTTS analysis as shown by Rahman [22]. 


\section{Synthetic Seismic Trace and Time-Shift Calculation}

Source function, $f(t)$ and seismic trace, $y(t)$ are needed to obtain time-shift $T$ in the FTTS analysis as shown in Eqs. (1-3). It has also mentioned that the source function can be varied according to target desired. Here, it is used impulsive dynamite source [23] in this article as:

$$
f(t)=\operatorname{Sin}(\alpha) \frac{e^{-\alpha t^{2}}}{\beta}
$$

where, $\alpha$ and $\beta$ determine the maximum length of time ( $\alpha=2 \pi f$ and $\beta=$ constant).

Using Eqs. (1) and (4) composite seismic traces are implemented as shown in Fig. 2.
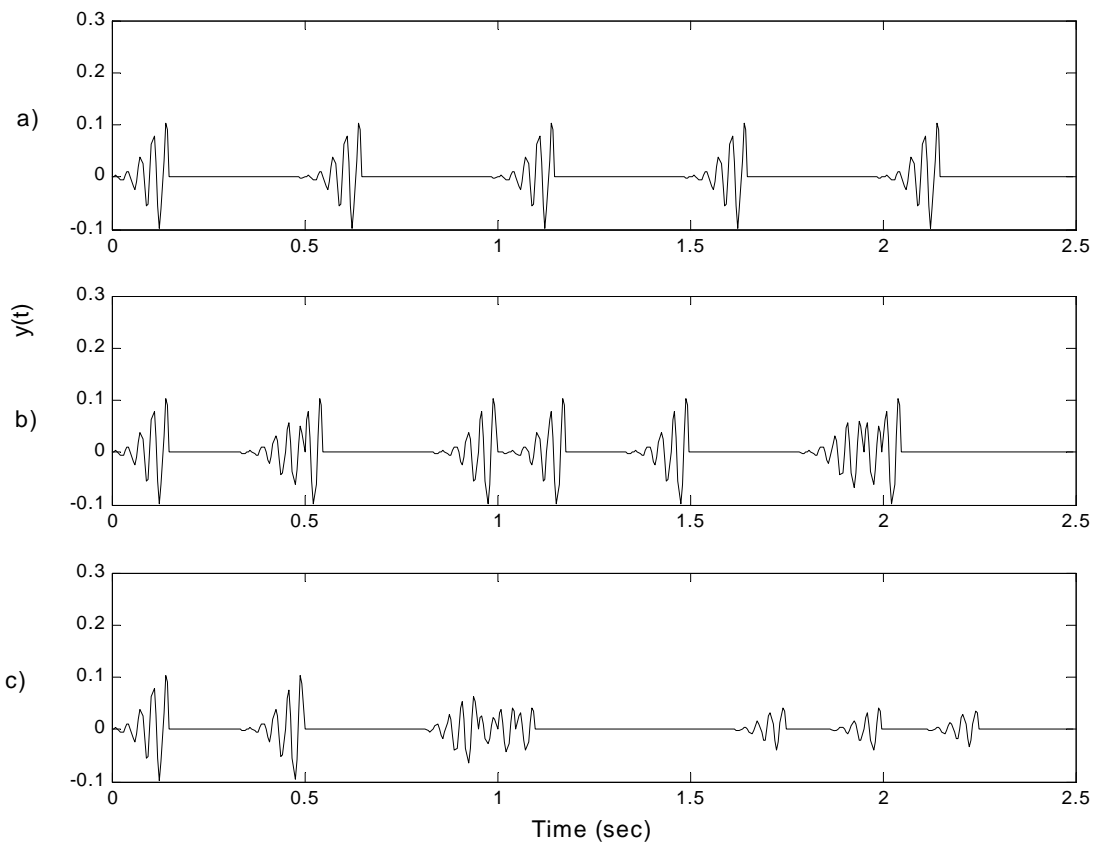

Fig. 2. Composite seismic traces, a) equally spaced time-shifts $T$ with constant amplitude, b) unequally spaced time-shifts $T$ with constant amplitude and c) unequally spaced time-shifts $T$ with varying amplitude.

In composite seismic traces, each of the reflections is prepared with different timeshifted source functions. Fig. 2(a-c) shows three composite seismic traces made with the values of $f=30 \mathrm{~Hz}, \alpha=188.50$ and $\beta=9$ along with different amplitudes constants. Four time-shifts (Fig. 2a) and eight time-shifts with constant and varied amplitude (Fig. 2b-c) composite seismic traces are implemented for analysis. Source functions at timeshift $T=0$ are also added in the composite seismic traces. Each of the time-shifts in Fig. 2(a) can be identified easily with straightforward observation. The task becomes 
complicated for Fig. 2(b-c). In Fig. 2(b), there are very close time-shifts at around 0.5 and $2.0 \mathrm{sec}$ respectively. Further complicated seismic trace is also prepared as shown in Fig. 2(c), where four time-shifts are at around $1.0 \mathrm{sec}$ and amplitudes are also varying. However, using FTTS analysis the time-shifts of the traces are resolved in the following section.

The power spectra of the composite traces are made as shown respectively in Fig. 3 (ac). Maximum energy in the spectral distribution is found at $30 \mathrm{~Hz}$. Using Eqs. (2) and (3) time-shifts are calculated for the composite seismic traces. Resolved time-shifts with appropriate amplitude coefficients are shown in Fig. 4 (a-c).

FTTS analysis can be extended for the unknown source function of traces as well. Spectral energy distribution of the trace can be used to make an image source. The frequency at where the maximum energy found in the spectral energy distribution of the trace can be taken as the source frequency. This frequency would be used for an image source in an appropriate type source function. However, accuracy depends on the delineation of source function. The FTTS analyses are made for INDEPTH seismic data in the following section delineating an image source.

a)

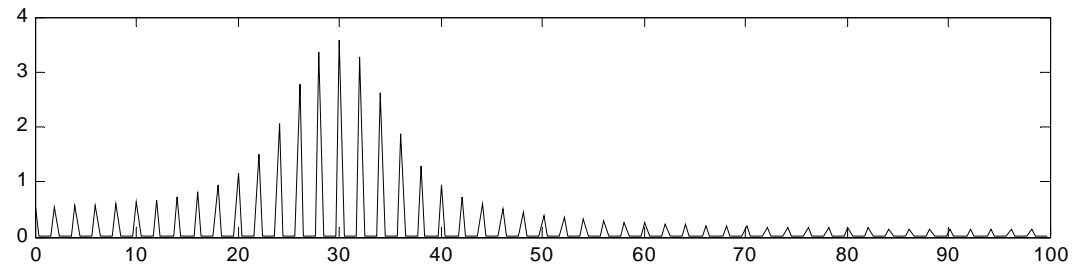

b)

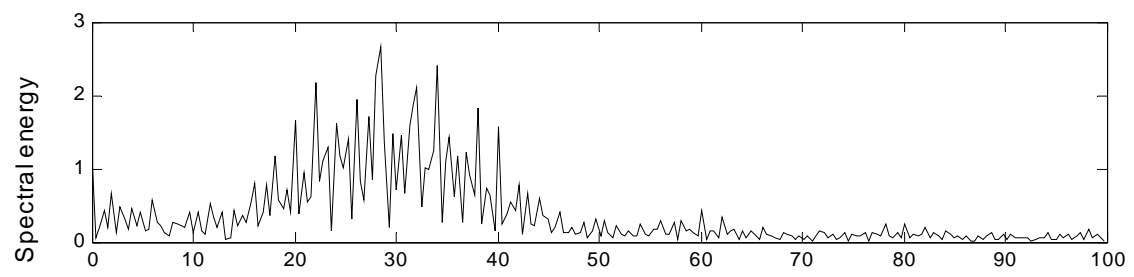

c)

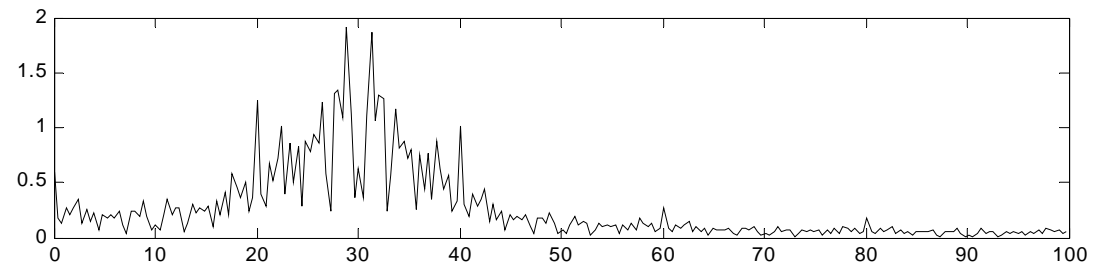

Fig. 3. Power spectrum of composite seismic traces as shown in Fig. 2(a-c) respectively 
a)

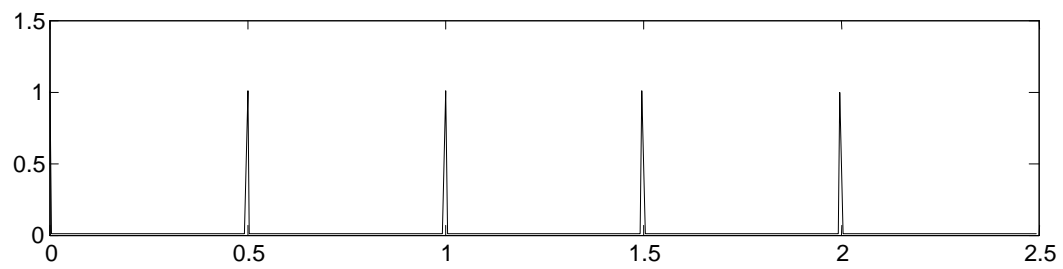

b)

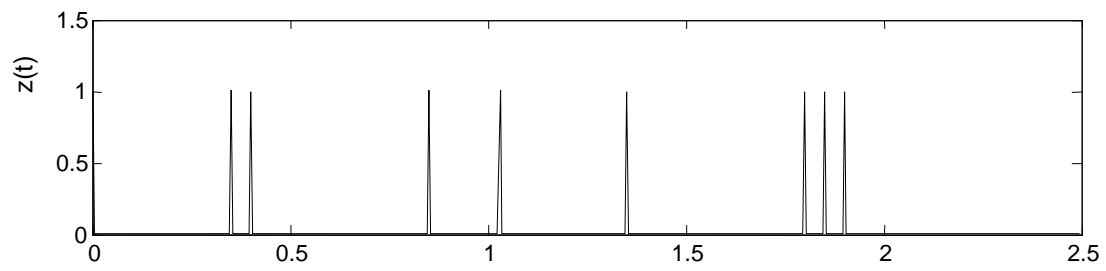

c)

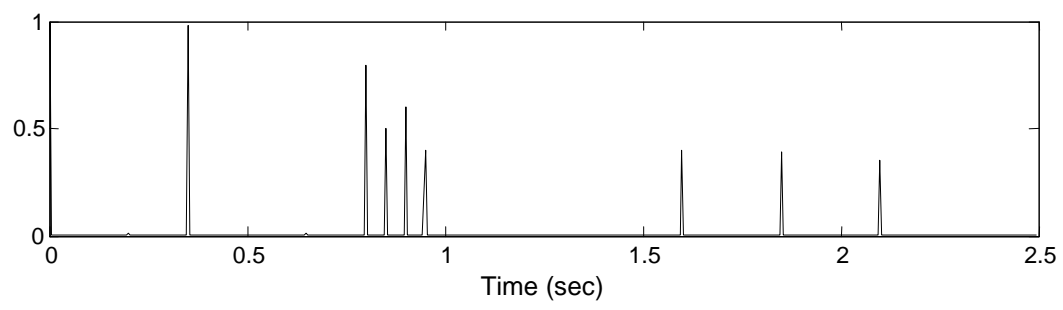

Fig. 4. Obtained time-shifts $T$ with FTTS analysis of the seismic traces as shown in Fig. 2.

\section{INDEPTH Seismic Data and FTTS Analysis}

The second phase of the Project INDEPTH is cored by about $200 \mathrm{~km}$ of deep seismic reflection profiling in the summer 1994 [16]. The reflection profiling and associated wideangle recording are spanned over $300 \mathrm{~km}$ from the High Himalayas in the south to the central Tibetan Plateau in the north. Broad-band recording of teleseismic events and geologic field mapping has been made up the rest of the project activities. Seismic crew of the Ministry of Geology and Mineral Resources (MGMR) of the People's Republic of China acquired CMP reflection data along nine profile segments with a total length of about $250 \mathrm{~km}$ stretching from the Crystalline Himalaya northward into the Tibetan Plateau. Explosive sources, mostly boreholes containing 50 to $200 \mathrm{~kg}$ dynamite, were triggered every $200 \mathrm{~m}$ along the profile and recorded by a $6 \mathrm{~km}$-long, 240-channel receiver spread. Data have been processed to produce 15 -fold stacked sections of the line segments $[14,24]$. In this work, analysis has been made for the unmigrated seismic line segments Tib 6 and Tib 7 (detailed data can be found from Makovsky and Klemperer [15]), Yangbajain Graben of Lhasa Terrane (Fig. 1) up to $10 \mathrm{sec}$ (twt). Unmigrated 


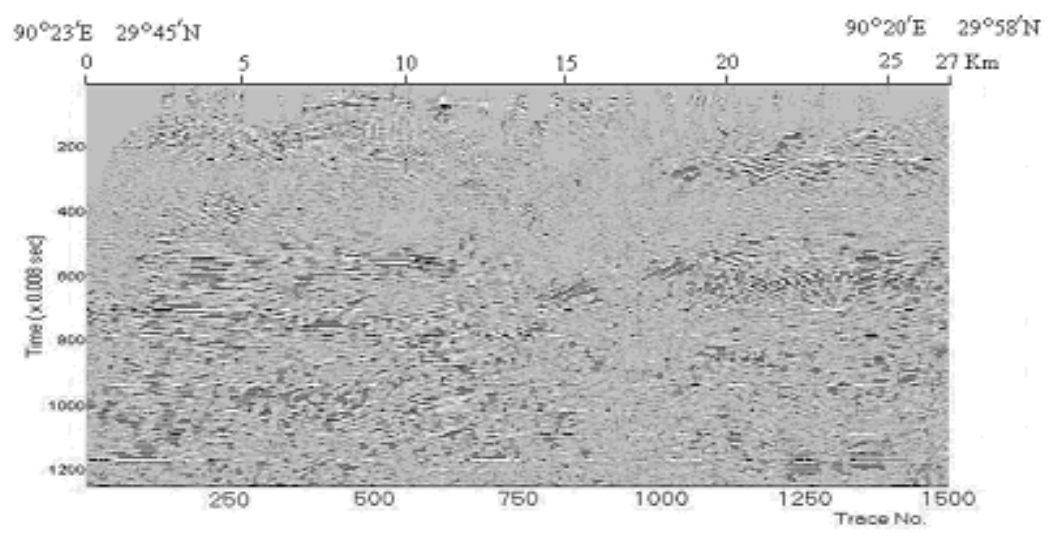

Fig. 5. 15-fold stacked unmigrated seismic section of CMP profile Tib 6, Yangbajain Graben, Lhasa Terrane.

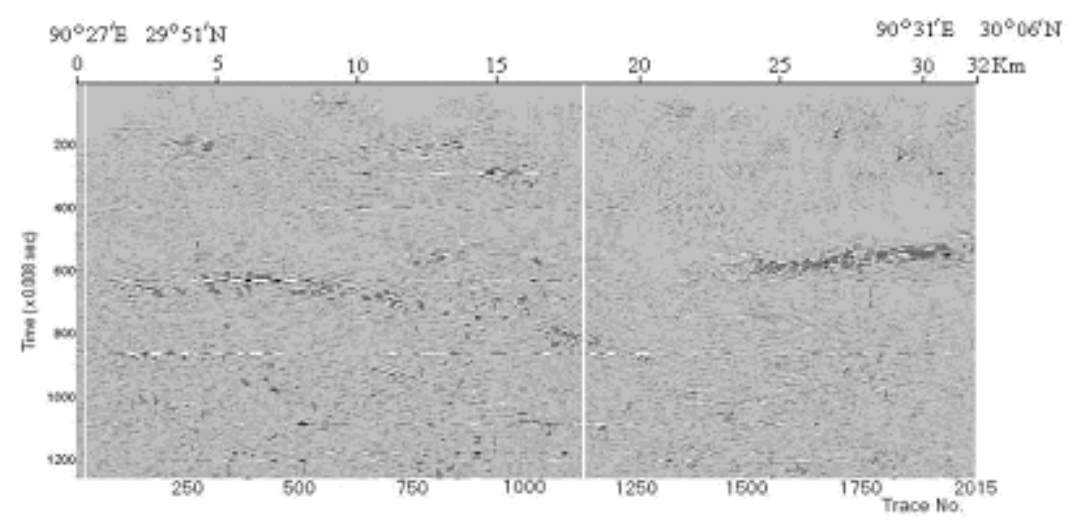

Fig. 6. 15-fold stacked unmigrated seismic section of CMP profile Tib 7, Yangbajain Graben, Lhasa Terrane.

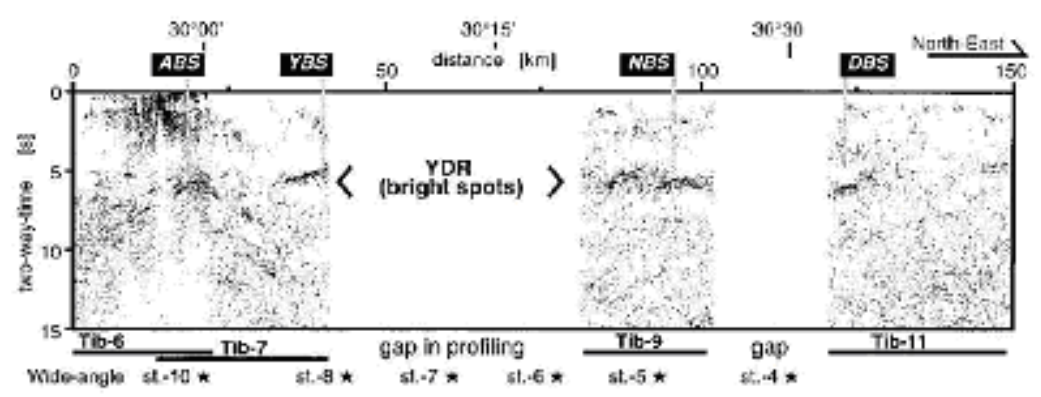

Fig. 7. Combined INDEPTH CMP profiles Tib 6 to 11. Each reflection-profile is marked below the sections, together with wide angle stations (stars). Bright-spots characteristics are imaged at 5 to 6 sec two way time and marked as ABS, YBS, NBS and DBS (after Brown et al. [14]). 
seismic sections are shown in Figs. 5 and 6. Combined INDEPTH CMP profiles, Tib 6 to 11 are also shown in Fig. 7 contained few previous findings.

The source is unknown for the attempted analysis of the seismic sections therefore the frequency of source function is determined with spectral analysis of few traces of the seismic sections Tib 6 and Tib 7. In most of the cases, not shown here but found the maximum energy distributions are at a frequency of $15 \mathrm{~Hz}$ as shown by Rahman [22]. Bording's [23] impulsive dynamite type source function is used to make image source for analysis. Using Eqs. (2) and (3) impulses responses of both the two sections (Tib 6 and Tib 7) are successfully implemented and shown in Figs. 8 and 9. It is found very effective amplitude contrasts (impulse response) of the whole sections. Major stratigraphic boundaries are seemed visible and pencil work can be made over the interested regions for studying geology of the area. Few geologic events are explained below from the analyzed seismic images.

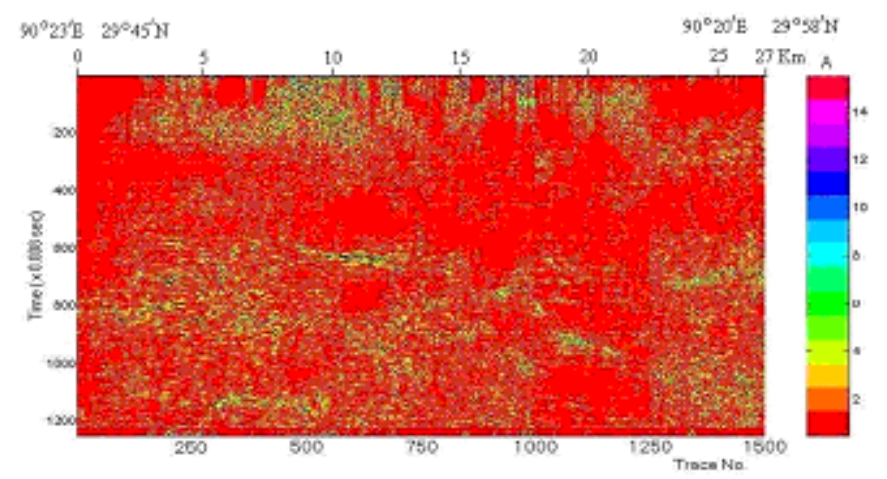

Fig. 8. FTTS analyzed seismic images of Tib 6 profile of Yangbajain Graben, Lhasa Terrane. A denotes the amplitude.

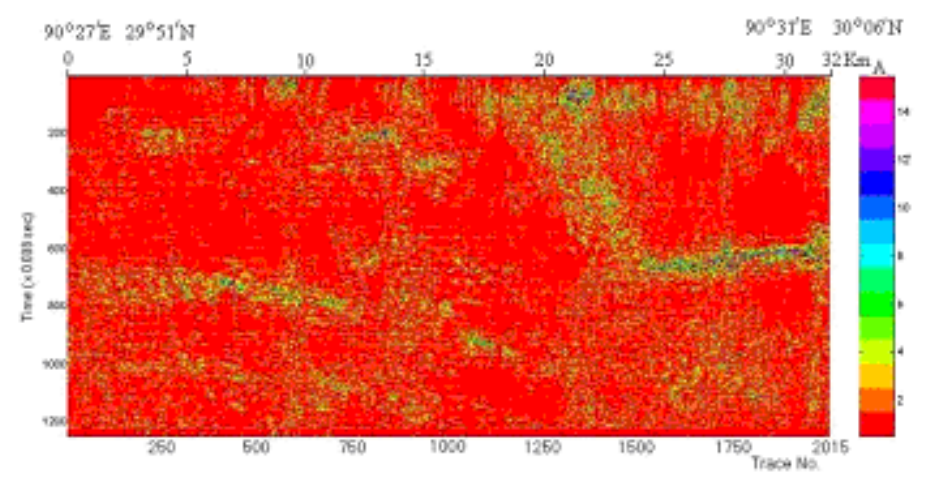

Fig. 9. FTTS analyzed seismic images of Tib 7 profile of Yangbajain Graben, Lhasa Terrane. A denotes the amplitude. 


\section{Results and Discussions}

The implemented seismic images (Figs. 8 and 9) with FTTS analysis of the profiles of Tib 6 and Tib 7 of INDEPTH data have shown similar Tibetan bright spots ABS and YBS (Fig. 7) as made by Brown et a.l [14]. The differences have been observed as the bright spot YBS is more precise in Tib 7 sections in between 5 and 6 sec in the present analysis. The extension from south to north end of YBS bright spot is not being remarkably visible (Fig. 7) in the whole section shown by Brown et al. [14]. However, it is clearly observed in this analysis (Fig. 9) and the bright spot YBS is started from surface which is inferred in Brown's et al. [14] section and later settled horizontally towards the north end in between 5-6 sec. The bright spot YBS is also observed with sharp impulse responses in Fig. 9. On other hand the bright spot ABS is not marked remarkably in the present analysis and found little wider (Fig. 8). The observed bright spots ABS and YBS might be the indication of different geological settings, as the Tibetan bright spots are said that the indication of same properties of the presence of free aquas fluid [14, 15, 25]. In an article to estimate the moho depth of the region Rahman et al. [20] has shown with frequency attributes analysis that the geologic structure of central Tibet are very complicated. Present analysis is also indicating the same results. The bright spots ABS and YBS are not found as same and continues as a band of bright spot reflections has been imaged by the INDEPTH project at about $15 \mathrm{~km}$ depth along $150 \mathrm{~km}$ of the Yadong-Gulu-rift, southern Tibet [15] rather present analyses have shown bright spot ABS little wider and YBS may not the extension of other bright spots. YBS bright spot is originated from the surface. This evidence is suggested the different geologic setting of the area, more specifically it can be said that there is an intermediate strong tilted support upholding the northern geology. It can also assumed that below the support towards the left (Fig. 9) there is a big gap which can accelerate further crustal changes of the area. It is also observed very irregular high impulse responses all over the sections but not formed as usual geologic pattern, which can be taken also an indication of occurring further crustal changes.

\section{Conclusion}

Unwanted events which are generally added to the practical seismic traces are not considered in this work. Most of such events can be eliminated using several filtering methodologies. For the unknown source function, the technique might suffer to estimate accurate impulse responses. In exploration seismology, most of the time, sources are known, hence FTTS analysis can be applied with minimum effort. However, for the earthquake seismology, the technique needs to be delineated the source function before apply it to ground accelerated earthquake wave. The source function of the seismic sections used in the present analysis is also unknown, instead the defined source has produced good impulse responses. Analyzed seismic images have shown remarkable crustal structure of the central Tibet particularly the high probability of further crustal change of the region. In some extent, the technique used in this work can be applied to 
detect very thin subsurface layers as very thin time-shifts have also resolved (Fig. 4). AVO analysis in seismic processing is challenging task to quantify thin subsurface layers in the amplitude map of the seismic data. The present analysis might be an addition in processing and interpretation of seismic data.

\section{Acknowledgements}

The authors acknowledge Dr. Larry D. Brown, Institute for the Study of the Continents, Cornell University, Ithaca, N.Y. and the Project INDEPTH team for making data available through web site (http://www.geo.cornell.edu/geology/indepth/indepth.html). The authors also acknowledge Dr. Thomas Mejer Hansen, Niels Bohr Institute for Astronomy, Physics and Geophysics, University of Copenhagen, Denmark for providing the support of reading segy data in matlab environment.

\section{References}

1. C. B. Stone, in Petroleum Geology- Bright spot techniques in Developments, ed. G. D. Hobson (Applied Science Publishers, London, 1977) pp. 275-291.

2. J. L. Allen and C. P. Peddy, Amplitude Variation with Offset: Gulf Coast Case Studies, (Society of Exploration Geophysicists, Tulsa, 1993) p. 126.

3. M. J. Jarchow, G. A. R. D. Catchings, and W. D. Mooney, Journal of Geophysical Research 98, B12 (1993). doi:10.1029/93JB02021

4. S. Matsumoto and A. Hasegawa, Journal of Geophysical Research 101, B2 (1996). doi:10.1029/95JB02883

5. A. R. Sanford, O. Alptekin, and T. R. Toppozada, Bulletin of the Seismological Society of America 63, (1973).

6. R. C. Bailey, Geophysical Research Letters 17, 8 (1990).

7. T. L. Pratt, J. F. Mondary, L. D. Brown, N. I. Christensen and S. H., Danbom, Journal of Geophysical Research 98, B10 (1993).

8. T. D. Jones and A. Nur, Journal of Geophysical Research 89, B11 (1984).

9. G. M. Cameli, I. Dini, and D. Liotta, Tectonophysics 224, 4 (1993). doi:10.1016/00401951(93)90041-H

10. T. Ryberg and G.S. Fuis, in General Results and New Methods ed. S. L. Klemperer et al. (Tectonophysics, 286, 1998) pp. 31-46.

11. W. J. Ostrander, Geophysics 49, 10 (1984). doi:10.1190/1.1441571

12. J. P. Castagna amd M. M. Backus, in Investigations in Geophysics Series, ed. M. R. Cooper (Society of Exploration Geophysicists, Tulsa, 1993) p. 348.

13. Xian-Yun $\mathrm{Wu}$ and $\mathrm{Ru}-\mathrm{Shan} \mathrm{Wu}$, AVO Modeling Using One-return Approximation-Proc. Society of Exploration Geophysicists International Exposition and Annual Meeting, San Antonio, Texas, September 9-14, 2001.

14. L. D. Brown, W. Zhao, K. D. Nelson, M. Hauck, D. Alsdorf, A. Ross, M. Cogan, M. Clark, and X. Liu, J. Chem. Science 274, 5293 (1996). 
15. Y. Makovsky and S. L. Klemperer, Journal of Geophysical Research 104, B5 (1999). doi:10.1029/1998JB900074

16. K. D. Nelson, W. Zhao, L. D. Brown, J. Kuo, J. Che, X. Liu, S. L. Klemperer, Y. Makovsky, P. Meissner, J. Mechie, R. Kind, F. Ni. J. Wenzel, J. Nabelek, L. Chen, H. Tan, W. Wei, A. G. Jones, J. Booker, M. Unsworth, W.S.F. Kidd, M. Hauck, D. Alsdorf, A. Ross, M. Cogan, C. Wu, E. Sandvol, and M. Edwards, Science 274, 5293 (1996).

17. P. Steeghs and G. Drijkoningen, Geophysics 66, 6 (2001). doi:10.1190/1.1487136

18. M. A. Rahman, S. M. Rahman, M. R. Islam, and M. Keramat, Journal of the Geological Society of India 71, 5 (2008).

19. S. M. Rahman, M. R. Islam, M. Keramat, M. S. Islam, and S. E. Ullah, Geophysical Journal 29, (2007).

20. S. M. Rahman, M. R. Islam, M. Keramat, and M. S. Islam, and A. A. Khan, Deep Crustal structure and estimation of Moho in the Lhasa Terrane of Central Tibet-Proc. of the International Seminar on Global Environmental-cum Ecological Challenges and Sustainability: Statistical Issues, University of Rajshahi, Bangladesh, December 2006.

21. L. D. Brown, An Evaluation of Sino-US collaborative activities during Phase II Preliminary Draft, Project INDEPTH, (Institute for the Study of the Continents, Cornell University, Ithaca, N.Y., 1994) p. 13.

22. S. M. Rahman, Ph.D. Thesis, University of Rajshahi, Rajshahi, Bangladesh (2006).

23. P. Bording, Seismic Wave Propagation Modeling and Inversion (Computational Science Education Project, University of Leeds, UK, 1995) p. 60.

24. D. Alsdorf, L. D. Brown, K. D. Nelson, Y. Makovsky, S. L. Klemperer, and W. Zhao, Tectonics 17, 4 (1998). doi:10.1029/98TC01315

25. S. M. Rahman, M. R. Islam, M. Keramat, and M. S. Islam, Journal of the Geological Society of India 69, 4 (2007). 